\title{
Construyendo miedos: imaginarios y narrativas mediáticas de la violencia
}

\author{
Building fears: imaginaries and media narratives of violence
}

\author{
William Fredy Aguilar Rodríguez wf.aguilar@uta.edu.ec \\ http://orcid.org/0000-0001-8291-0216 \\ Universidad Técnica de Ambato (Ecuador) \\ Leonardo Xavier Brito-Alvarado Ix.brito@uta.edu.ec \\ http://orcid.org/0000-0001-8593-3691 \\ Universidad Técnica de Ambato (Ecuador)
}

\section{Resumen}

El presente artículo se inscribe en el contexto de la investigación en curso "Sobre la construcción social del miedo. Relatos sobre los alcances de las violencias entre jóvenes", de la Dirección de Investigación y Desarrollo (DIDE) Universidad Técnica de Ambato, Ecuador.

A partir de una sistematización de lecturas sobre el riesgo, violencia y miedos provenientes de la antropología, sociología y la comunicación, el objetivo principal es cartografiar mediatamente estos discursos como relatos que han sido asumidos como algo propio, normal y cotidiano por parte de la población. En este sentido, los relatos del miedo tienen un componente muy importante en las imágenes que facilitan la apropiación por parte de la ciudadanía. Por ello, el 
análisis de las imágenes sobre violencia y miedos constituye una forma de entender las dinámicas sobre seguridad ciudadana.

Palabras clave: Riesgo; violencia; miedos; medios de comunicación.

Abstract

This article is part of the ongoing research "On the social construction of fear. Stories about the scope of violence among young people" of the Directorate of Research and Development (DIDE) Technical University of Ambato, Ecuador.

Based on a systematization of readings on risk, violence and fears coming from anthropology, sociology and communication, the main objevtive is to map these discourses mediately as stories that have been assumed as something proper, normal and daily by the population. In this sense, the stories of fearhave a very important component in the images that facilitate the appropriation by the citizenship, for that reason the analysis of the images about violence and fears constitutes a way to understand the dynamics about citizen security.

Keywords: Risk, violence, fears, media.

La Teoría Social (Beck, 2006; Kessler, 2009) ha asumido el debate y las propuestas teóricas sobre el riesgo contemporáneo, es decir, una teoría social del riesgo (Beck, 2006). Para Ulrich Beck (2006) vivimos en 'sociedades del riesgo' que se caracterizanpor una creciente inseguridad manifestada por diversas formas y acciones (ecológicas, reparto de riqueza, contaminación, entre otras). Estas 'sociedades del riesgo' son una característica de la modernidad en el sentido de identificar temores generalizados en las poblaciones. De acuerdo con Antonhy Giddens (1997) la noción de riesgo aparece en el pensamiento europeo en el siglo $\mathrm{XIX}$ debido a los cambios especialmente industriales que alteraban tanto la sociedad como a la naturaleza. Mientras Niklas Luhmann (1997) argumenta que la modernidad tieneal riesgo como discursosocial que altera la normalidad cotidiana de la humanidad debido a los cambios sociales, económicos, productivos y tecnológicos que generara la modernidad.

Siguiendo a Kessler (2009) la teorización del riesgo seha insertado dentro de los discursos del Estado de Bienestar desde finales del siglo XIX como una propuesta del nuevo derecho laboral enmarcado en la protección de los trabajadores industriales. A partir de esto el riego se 
configuró como un modo de administración de la seguridad laboral y posteriormente se fue ampliando a otros escenarios como el policial y militar.

De esta manera el riego es un discurso social y como tal posee una semántica propia,para Beck (2006) lleno de amenazas futuras originadas en el presente. Por esto, "la industrialización ha producido riqueza y bienestar, pero también inseguridad y contingencia. El riesgo es presentado como un concepto dual y paradójico, cuyas caras son la oportunidad y el peligro" (Rosas-Cobos, Sasia-Santos, 2016: 22). Así la noción de riesgo se ha enfocado en anticipar las probabilidades de accidentes, sentando "las bases modernas de los seguros sociales y privados" (Kessler, 2009: 59).

El cambio de las sociedades industriales a las postindustriales ha traído nuevos riesgos, miedos y violencias debido al desgaste del Estado de bienestar (1) y el fortalecimiento de las corporaciones privadas que han debilitado muchas políticas sociales como: laborales, educativas, entre otros, que a su vez, han creado profundas divisiones sociales y con ello el aparecimiento de nuevas formas de violencias. De esta manera:

Esto implica un cambio estructural dado que se trata del abandono de la sociedad salarial, en la que el trabajo protegido era el eje estructurador de la sociedad y dotaba de certidumbre sobre el futuro a los ciudadanos. Esta situación ha ocasionado un nuevo aumento de los procesos de individualización y un aumento masivo de la inseguridad social" (Ochoa, 2014: 9).

A partir de esto se puede comprender al riesgo desde una visión más crítica, así tenemos que es: "un acontecimiento que compromete la capacidad de los individuos para asegurar por sí mismos su independencia social. Si no se está protegido contra estas contingencias, se vive en la inseguridad (Castel, 2003: 35).

Por tanto, y como lo sugiere Gérard Imbert (2008), en las sociedades llamadas posmodernas (2) el riesgo ha tomado varios matices discursivos de violencia; una enfocada en la violencia altamente riesgosa para los cimientos de las sociedades como el terrorismo y los conflictos étnicos, lo que Imbert denomina violencia dura; y otra las violencias menores como el vandalismo. A esto se añade una violencia lúdica (3) basada en la búsqueda de sensaciones extremas como el alcohol, las drogas, entre otras, que pueden llegar a convertirse en una violencia indiscriminada.Por consiguiente:

[...] La sociedad actual se caracteriza por un sistema económico que genera riesgos tecnológicos, ecológicos y sociales desconocidos hasta el momento y una magnitud que 
devienen inasegurables [...] el mundo donde se ha generado una intensa división del trabajo, se diluye la responsabilidad sobre el riesgo, puesto que cada eventual responsable puede descargar si culpa en otras partes interdependientes (Kessler, 2009: 59).

En estados de riesgos, catástrofes y miedos los ciudadanos buscan en los medios de comunicación un espacio para enfrentar sus temores y angustias, y a la vez, las respuestas para desenvolverse frente a estas situaciones. Los relatos mediáticos de riesgos, catástrofes y miedos son el gran imán de los medios de comunicación, por ejemplo "la escalada de violencias en las ciudades del continente, la precarización laboral y su correlato [...] gana en legitimidad" (Reguillo, 2008: 7).

El estudio de la violencia no es un tema nuevo en el escenario de las ciencias sociales, por ejemplo, desde la antropología Philippe Bourgois (2009) la cual argumenta que la violencia castiga desproporcionadamente a los sectores más vulnerables de la sociedad; y cuando esta no es reconocida se hace cotidiana, aceptada y legitimada. Los tipos de violencia pueden agruparse, siguiendo la lógica de Bourgois (2002) en política, estructural, simbólica y cotidiana. La violencia política se interrelaciona estrechamente con la violencia directa o intencional, y es administrada en el nombre de una ideología política, un discurso de la legítima monopolización de la fuerza por parte de los Estados o caso contario por la disputa del poder por parte de grupos beligerantes, esta no debe confundirse con operaciones del crimen organizado. "Tal como la represión física de los disidentes por la Fuerzas Armadas y la policía o su contrario, la lucha armada popular contra un régimen represivo" (Bourgois, 2002: 75).

La violencia estructural se determina por la organización política-económica de las sociedades que imponen determinadas condiciones de sufrimiento físico y emocional a los sectores más vulnerables, esta violencia abarca desde la morbosidad, la pobreza y las condiciones de trabajo abusivo que se concentra en una disputa por la redistribución del poder (Bourgois, 2009). Este tipo de violencia fue utilizado, especialmente, por los antropólogos médicos (Epele, 2010; Scheper-Hughes, 1997) para referirse a las desigualdades económicas y sociales causantes de ciertas enfermedades y del sufrimiento social en poblaciones marginales.

Mientras, que la violencia simbólica, en términos de Pierre Bourdieu (2001) constituye una dominación que opera en un nivel íntimo de las personas debido a un reconocimientodesconocimiento de las estructuras de poder, de manera especial, por los dominados que tienden a cooperan con su propia opresión, haciendo aparecer a esta como algo normal, cotidiana y necesaria creando una serie de relaciones sociales de dominación. Por último, la violencia cotidiana es aquella que es utilizada para describir los 'crímenes en tiempos de paz' son los pequeños conflictos invisibles dentro de una sociedad, como lo describe Bourgois: 
[...] La noción a las prácticas y a las expresiones de agresión interpersonal que sirven para normalizar la violencia en el nivel micro, tales como la pelea sexual y doméstica y la delincuencia, e incluso la drogadicción. La importancia analítica del término es la de evitar la explicación de la confrontación a nivel individual desde miradas psicológicas que culpen a las víctimas (2002: 76).

\section{Las narrativas mediáticas del miedo}

Para Freud, el miedo hay que interpretarlo como una de las mayores causas y en ocasiones, efectos de la angustia y sufrimiento de la gente, identificando la existencia de un miedo racional y comprensible que surge como reacción naturalizada ante la percepción de un peligro inminente, aun cuando la comprensión hacia ciertos objetos y situaciones dependerá, en la mayoría de los casos, "de nuestro conocimiento, de ellos así como de nuestra sensación de poder sobre el mundo exterior" (Freud, 1991: 233).

Para Norbert Elias (2000) la intensidad, tipo y características de los miedos y ansiedades que se hacen presente en el individuo nunca dependen de su propia 'naturaleza' sino que están determinados tanto por la historia social y de estructura que maneja la persona, es decir, de la práctica de las relaciones sociales que entabla dentro de su medio. Por tanto, y siguiendo a Berger, (2001) cuando se reconozca que el miedo se lo adquiere conforme las experiencias que el ser humano adquiera durante su vida, ser un producto de la construcción socialoriginaria de la interacción con otros produce que el miedo cobre un significado mayor mediante las claves de interpretación que la población reconoce como ciertas. En este punto es donde el ser humano interioriza el miedo y lo asimila como algo 'propio'.

De acuerdo, a esto, no todas las personas perciben el miedo de la misma forma y más aún, no lo interiorizan de igual manera. En primer lugar, hay que entender que el miedo se produce y reproduce dentro de la comunidad emocional, en la cual, el miedo está presente en cada uno de los sujetos determinados como víctimas o potenciales víctimas, haciendo parte de una comunidad del dolor (Scheper-Hughes, 1997).

El problema radica en la normalización del miedo que naturaliza el temor dentro de la población. No obstante, no lo hacen de forma general, pueden diferenciarse por su sexo, edad, religión, estado civil ente otras. Sin embargo, el miedo no sólo se hace presente en un determinado contexto, sino que se expande a nivel local y luego a nivel global mediante los medios de comunicación producto de los procesos de globalización. Estos dos niveles de 
reproducción del miedo no funcionan como estratos separados de la experiencia, sino que se articulan mutuamente "un miedo sólo puede volverse global si encuentra la manera de articularse en las dinámicas de constitución del miedo que tienen lugar en escenarios sociales concretos" (Ordóñez, 2006: 95).

El individuo aprende a evaluar si una situación es amenazante o no; de ahí que, el sujeto apoyará su apreciación de la situación mediante la interpretación de caracteres o significados que muestren una posibilidad de la existencia de algún tipo de temor. Es relevante mencionar que el miedo es una noción de carácter multidimensional que contiene elementos culturales, sociológicos, subjetivos y comportamentales, pudiendo manifestarse de diferentes maneras, dependiendo si se trata de un espacio concebido, percibido o vivido de la persona involucrada la cual va a proceder a interiorizar su realidad, incluyendo al miedo. Estos miedos pueden ser interpretados como una amenaza latente y desconocida porque muchas veces no se recuerda o no se tiene presente el momento que causó una reacción de alerta al miedo, induciendo ciertas claves o señales en el espacio social que nos refieren a estados de ansiedad y angustia, o bien, puede relacionarse con nuestra propia experiencia.

Las culturas mediáticas (García Canclini, 1989) evidencian un estado generalizado de violencia/guerra que ha sido un tema altamente debatido en América Latina. Para Carlos Monsiváis (2003) desde el decenio de los sesentas los medios de comunicación impresos han sido objeto de acusaciones por parte de ciertos sectores académicos, increpándolos por someter a la población a un constate bombardeo de imágenes y discursos violentos. Monsiváis cita a Neri Rivero (2001) para describir la construcción social de la violencia, la cual expone:

¿Cómo negarles o reprocharles a los niños que jueguen a guerritas, luchitas, a ser los superhéroes de la televisión, a policías y ladrones o nuevos Rambos, si las calles, los mercados, las escuelas y sus propios hogares están infestados de armas y violencia en todos los órdenes? (Monsiváis, 2003: 160).

Los medios de comunicación como la televisión desempeñan una doble posición, primero actúan como un espejodesde donde los ciudadanos pueden percibir las diferentes tipas de violencias, y en otro plano, son proveedores de mecanismo de protección social. Hoy la violencia, el miedo y el terrortienencabida dentro de esos medios, por el sensacionalismo existente, donde el morbo es la guía mediática.

Fernando Carrión (2008) sostiene que los mass media han privilegiar las notas periodísticas sobre violencias y los miedos por que los sujetos desean ver, oír o leer historias más cercanas a la gente, más aún cuando lo político y económico se ha concentrado en una serie de 
discursoprovenientes de 'ilustrados' que poseen un lenguaje distantes con las ciudadanías, lo que se ha llegado a denominar como 'populismo mediático'.

Este contexto, es que se asume que los medios de comunicación son potentes en la producción de imaginarios y deseos porque «han sido capaces de recuperar el "habla mítica" del pueblo, en el sentido de jugar con las ganas de experiencia, con la necesidad de un mundo trascendente que esté por encima de lo experimentado y que sea, paradójicamente, experimentable través del relato de los miedos en los medio (Reguillo, 2000: 195).

Esto convierte al miedo en un relato simbólico que nacen desde los medios de comunicación, y que es asumido por los ciudadanos como algo normal y cotidiano. "los efectos simbólicos de la (in) seguridad ciudadana son los miedos. Éstos son el resultado de múltiples y diversas producciones simbólicas, pero sobre todo, del trabajo, del mercado y los medios de comunicación" (Rincón y Rey, 2008: 35). Para Rossana Reguillo (2000) el miedo es un relato construido por la experiencia individual y colectivamentecompartida e inscrita dentro de una cultura.

El miedo es una forma de actuar frente al mundo, un modo de vivir que se construye alrededor de geografías del miedo y de 'mitologías urbanas' en torno al sida, al robo de órganos, a los secuestros, a la vulnerabilidad de las mujeres (Reguillo, 2000: 201).

Lo que Rincón y Rey (2008) han descrito a la violencia desde los medios como el surgimiento de una serie de historias sobre los miedos ciudadanos matizados alrededor de la idea 'basados en hechos reales', que ha significado una esfera de miedo social, creando una serie de imaginarios.

Susana Rotker (2000) alega que en una sociedad donde la violencia y el miedo están insertados todos somos potencialmente ciudadanos en peligro y a la vez sospechosos llenos de "vivencias cotidianas que apuntan al sentimiento urbano de indefensión generalizada y al riesgo de la parálisis o de la búsqueda de mecanismos represivos que logren controlar el descontrol" (Rotker, 2000: 16-17). Otra idea para considerar al miedo como el resultado de una 'política del terror' que nace como un relato de políticas públicas diseñadas por los gobiernos sobre el control y seguridad ciudadana (Mouffe, 2011). De esta manera, "El miedo es un argumento esencial de la política. Líder es quien apela al miedo, quien interpreta el miedo, quien encarna la respuesta primera frente al miedo [...] Su ética es creer que hay los buenos y los malos" (Gómez Buendía, 2004: 25). 
A mayor violencia los medios audiovisuales crean una serie de mensajes de protección social, y a su vez, publicidad de mercados de seguridad que incluyen artilugios tecnológicossobre protección, mientraslos discursos políticos promueven la creación de normas penales más severas para combatir a la delincuencia (Monsiváis, 2003). De esta manera, "a más miedos, más cuentos mediáticos del miedo: más publicaciones, más historias, más sensacionalismos, más individuo, más estigmatización, menos investigación, menos democracia" (Rincón y Rey, 2008: 35).

La violencia y su impacto social son atravesados por las explicaciones que brindan los mediosde comunicación audiovisual a la ciudadanía gracias a los expertos en seguridad, la violencia se basa en las narraciones periodísticas que tiende a convertirse en realidades y experiencias colectivas (Reguillo, 1996). Sin embargo, estas opiniones se convierten en una guía moldeadora de la población, un nuevo poder pastoral emanando de una autoridad mediática que diseña una ruptura de opiniones y la creación de estereotipos sociales, donde es así que "Los buenos contra los malos, los poderosos contra los débiles" (Reguillo, 1996: 24). Estos relatos conllevan a los ciudadanos a pensar que son potenciales víctimas delas violencias. La violencia y el miedoson aspectos de las relaciones sociales y los procesos de producción de subjetividades contemporáneas. La violencia y el miedo tienen afectos sobre los cuerpos y las mentesque pueden acarrear serios problemas de enfermedades corporales y mentales, y puede entenderse como una somatización de la vida, de esta manera:

\footnotetext{
El miedo se coliga con los fenómenos que fracturan la confianza sobre la que puede construirse la sociabilidad; todos ellos además están imbricados con las dificultades extraordinarias para reconocer al otro, para ensayar modos diversos de vivir la alteridad; así como con las condiciones existenciales definidas alrededor de las relaciones sociales de vecindad y solidaridad, y las formas particulares como se produce la subjetividad de los individuos para enfrentar el entorno, con sus dudas, incertidumbres y temores (Useche, 2008: 7).
}

De acuerdo a Beck (2006) esta situación conlleva la idea de pensar la capacidad del Estado para administrar la vida (cotidianidad de la población) reestructurando las prácticas de convivencia social dictando una serie de mecanismos (leyes) de exclusión y jerarquización en la población, y con ello una politización de las violencias y de los miedos. Esto permite a los Estados tener el control sobre las poseer dispositivos de poder de administración de la vida pública y privada.Por ello, el poder ya no reprime, sino que normaliza las prácticas de 
violencias y miedos, y es así que se han convertido en categorías y formas de vida tan cercanas a los sujetos.

En este sentido, los medios de comunicación poseen una doble pretensión, primero difunden los hechos de violencia pero simultáneamente dan la solución a esta problemática. De este modo el dramatismo mediático de informar al miedo se basa en cuatro ejes:

1) Los hechos delictivos se encuentran en crecimiento y diversificación, convirtiendo al delito en algo cotidiano.

2) Nuevos actores de violencia que a su vez han trasformado la forma de actuación, creando nuevos escenarios de miedo.

3) El alarmante uso de frases y palabras que causan una esfera de inseguridad sociale impunidad hacia los delincuentes.

4) La delincuencia ha encerrado a la sociedad que se ha convertido en su rehén, para salir de esta situación la sociedad demanda de medidas policiales y judiciales más severas. "El sujeto de lo peligroso se condensa en un personaje que es joven, de barrio marginal, habitante de ciertas fronteras consideradas "calientes"; otro cercano pero agresivo y normal; un sujeto claramente fuera de la sociedad. Así, el delito es una forma de imaginación/discriminación del otro (Rincón y Rey, 2008: 38).

Para Martín-Barbero (2004) los ciudadanos tienen miedo no por los asaltos o los asesinatos, sino por la 'angustia cultural' que provocan las narraciones mediáticas. Bajo este criterio las noticias de los actos de violencia pasan a convertirse en parte de una'normalidad social'. Por tanto, la violencia no se basa en debates ideológicos o económicos, sino en lo simbólico mediático. Por ello Jean Baudrillard (1976) describe una configuración que muchas veces, nuestra percepción de vida y también de la muerte, y es porque vivimos de muerte lenta por lo que soñamos con una muerte violenta.

Esta comprensión sobre la violencia, el horror y la muerte es una forma para comprender los fenómenos culturales que se producen dentro de las sociedades. James Clifford (1996) describe que cada sociedad posee un universo simbólico propio que rige las actividades cotidianas. En este sentido, los medios de comunicación producen y circulan miedos, las ciudadanías piden a las autoridades políticas públicas de seguridad más enérgicas. Martín Caparrós (2009) ha denominado a esta situación comoseguritización, una desconfianza hacia el otro, y así justificar el autoritarismo político. Rincón (2016) arguye algunas características del seguritismo:

1. Crear un sujeto que viva aterrorizado, una víctima directa o indirecta de la violencia. 
2. Un pacto de convivencia social donde los espacios públicos son el centro de la delincuencia y los espacios privados edenes de seguridad, fomentando la privatización de la seguridad y de los espacios públicos.

3. Visualizar a los otros como enemigos, enemigos de la idea de lo blanco, es decir, lo indio, negro, migrante y los jóvenes.

4. Festejo de una vida llena de histeria colectiva matizada por el miedo de lo extraño y la desconfianza.

5. La implementación de políticas de seguridad conservadora limitante de los derechos humanos.

6. Una política rentable, los discursos políticos sobre seguridad están por encima de la educación, salud, hay que proteger a la propiedad y a la vida en ese orden.

7. Un buen negocio es el mercado de seguridad que ofrece un amplio mercado de productos destinados a resguardar a la propiedad.

8. Otro modo de éxito político y empresarial es la regulación de seguridad, propuestas para proteger a los sectores empresariales, a más seguridad, más empelo, menos inseguridad, por tanto, más felices (Rincón, 2016: 299-300).

\section{La espectacularización visual de la violencia y del miedo}

En América Latina parecería que existe una fascinación por ver a la violencia, y que mejor la fotografía que conquista nuestros imaginarios sobre la muerte y horror, quizás esto se deba a que nuestra historia(s) es llena de estos relatosdesde el tiempo de las colonias América Latinaha vivido bajo el imperativo de "[...] los controles y las garantías del orden judicial [...] donde la violencia del estado de excepción supuestamente opera al servicio de la civilización" (Membe, 2011: 40).

El constante bombardeo mediático hace que la violencia se convierta en parte de las cotidianidades sociales, creando espacios 'semióticos' complejos donde la lucha del bien contra el mal se justifica y para ello es necesariocrear una escenificación espectacular, así tenemos:

Justifican la aparición de "vigilantes" o la aplicación de la justicia por propia mano. En estos casos, el vigilante se convierte en tal por su condición de antigua víctima: se trata generalmente de varón blanco (aunque con la tendencia políticamente correcta, ya son varias las mujeres y los negros que se convierten en vigilantes), profesionista exitoso; habitante de los" suburbios"; ciudadano ejemplar y pacífico y contribuyente, respetuoso de las leyes y creyente (Reguillo, 1996: 26). 
La violencia cualquiera sea evoca a la idea de horror entendido como una contraposición a lo moralmente aceptado por una sociedad. Tanto la violencia como el miedo se han establecido como algo cotidiano, de manera especial, en occidente donde los medios de comunicación (televisión, medios impresos, redes sociales) han trazado un discurso visual para representarlo como un discurso icónico, espectacular y cercano, de ahí la violencia y el horror sean lo más reiterativo en los discurso mediáticos que establecen una dicotomía ética de la mirada entendida como 'biplanar' (4):

[...] El primer nivel ético concierne al respeto por la agonía de los individuos retratados, mientras que el segundo atañe a la salvaguarda de quienes asisten a las representaciones icónicas terribles protagonizadas por los primeros. De modo que por un lado se teme una espectacularización de las desgracias ajenas, lesiva para la dignidad de los sujetos representados, y por el otro, se desea proteger al público, a la audiencia de contenidos potencialmente ofensivos, perturbadores o susceptibles de mímesis conductual perjudicial (Marcia, 2014: 4).

Los medios de comunicación para Reguillo (1996) (televisión, diarios impresos) y en especial Internet han construido escenarios 'perfectos' para crear y circular todo tipo de narrativas de violencia, de horror y miedo haciéndolos parte de nuestras vidas.Vivimos y sentimos a la violencia de los otros como si fuera de nosotros para ser expuestas se ha domesticado en el sentido de que hemos acogida como propia la violencia.

\footnotetext{
[...] Se pueden crear situaciones de riesgo, de miedo y hasta de horror que tienen su reflejo por ejemplo en las producciones cinematográficas: las que llevan a una sistematización del horror en el cine gore, a la santificación de la muerte en las películas hardcore, a su hiperrealización en el snuff cinema; pero también, en la televisión actual, la creación de situaciones límite en los reality shows y otros juegos concursos, que crean estados de incertidumbre, instalan relaciones de dominación, puesta a prueba, humillación, situaciones que encierran una fuerte violencia simbólica; violencia que se manifiesta por otra parte en la trivialización de la muerte (Imbert, 2008: 114).
}

Esta situación ha llevado a crear un discurso de democratización mediática de la violencia,del horror y el miedo que se ampara en derecho a informar; la gente se siente atraída por las imágenes donde se muestre sangre convirtiendo a los medios en una metáfora de Drácula lo sangriento está por encima de cualquier derecho de la ciudadanía a recibir información 
adecuada, los neologismo hoy se han apoderado de los debates sociales más aun cuando internet ha dictado nuevas formas de apropiarse de la violencia, el horror y el miedo haciendo aparecer que su uso se 'suavice' entre los neologismos recurrentes encontramos a repulsion u horrid democracy (5). Es decir, "la violencia, hoy, se ha desacralizado, fenómeno acentuado por otra parte por la permanenteescenificación/repetición/serialización de hechos violentos en los medios de comunicación, hasta crear auténticos escenarios de violencia" (Imbert, 2008: 116).

Las fotografías sobre la violencia y el miedo, muchas veces, se encasillan en lo que se denomina como una 'pornografía visual' que termina por borrar al sujeto, despojándolo de su subjetividad, animalizándolo, convirtiéndolo en un objeto de contemplación, esta pérdida de subjetividad conlleva a la idea de que el ser humano es una cosa.

\begin{abstract}
Asistimos, pues, a una proliferación de nuevas formas y usos de violencia (no en términos cuantitativos sino cualitativo-formales): una violencia salvaje, de signo más bien gratuito, de objetivos indefinidos, aparentemente sin sentido, transgresión más o menos controlada, que consagra una verdadera cultura de la violencia tanto en actuaciones como en representaciones (Imbert, 2008: 116).
\end{abstract}

La fotografía debido a su forma técnica-mecánica de acción se asocia que siempre está conectada a la realidad, por tanto, las imágenes capturadas por sus lentes se convierten en testimonios verídicos, "así, las fotografías han desempeñado -y continúan desempeñando- un importante rol en los procesos de regulación política y social, constituyéndose en elementos clave para las estrategias comunicacionales de los poderes hegemónicos" (Lapenda, 2017: 1). Esto permite construir el nexo entre las fotografías y las violencias.Para John Tagg (2005) reflexionar a la violencia desde las fotografías es un ejercicio de poder simbólico que recala en la población es seducida por estas. Por ello las fotografías "nunca son 'prueba' de la historia; ellas mismas son lo histórico" (Tagg, 2005: 87). Las fotografías son parte de la interpretación de una realidad mediada por una cultura. La fotografía, es quizás, el medio de comunicación más democratizado gracias a que existen formas de ver e interpretar a las imágenes. Por ello "sabemos o lo que creemos saber afecta a nuestra mirada, abriéndose un camino hacia el análisis histórico, cultural y contextual [...] de la producción de imágenes visuales" (Ardévol, 2001: 18).

La imagen fotográfica se ha desarrollado, por lo menos, desde dos etapas; la primera anclada en la esfera del icono de la copia que alude a una realidad donde las miradas, interpretar una multiplicidad de imágenes. Una segunda etapa es la reproductibilidad modal que es la suma de 
las diversas características de la imagen fotográfica (reproducción, miradas diferentes, lecturas particulares, goces, estéticas) esta etapa es la consecuencia de los avances tecnológicos de la fotografía. Por ello:

La fotografía es mucho más que una imagen, entendida como una copia o reproducción del mundo real, es un espacio de negociación de poder y de la identidad, un espacio de reflexión teórica y metodológica, un medio de comunicación intercultural, un vínculo social, un medio de descubrimiento, un campo de experimentación (Ardévol, 20001: 23).

Las imágenes sobre la muerte han sido algo recurrente desde los inicios de la fotografía, convirtiéndose una fascinación poder congelar esos momentos como la muerte. La retratística post mortem (6) es utilizada para recordarnos no solo la violencia, sino de la efímera existencia que tenemos como seres vivos.

Si en las imágenes mortuorias privadas el objetivo de la puesta en escena era el embellecimiento del recuerdo, en los retratos póstumos de personas públicas, este objetivo pasa a ser paradójicamente la reorganización de la realidad para dar más verdad a la imagen y un mayor énfasis al mensaje que con ella quiere transmitirse (Cuarterolo, 2007: 85).

El acto fotográfico permite certificar una experiencia cotidianapara aceptarla o rechazarla, este acto se convierte en un recuerdo. Es de esta manera:

Una fotografía no es el mero resultado del encuentro entre un acontecimiento y un fotógrafo; hacer imágenes es un acontecimiento en sí mismo, y uno que se arroga derechos cada vez más perentorios para interferir, invadir o ignorar lo que esté sucediendo. Nuestra percepción misma de la situación ahora se articula por las intervenciones de la cámara. La omnipresencia de las cámaras insinúa de modo persuasivo que el tiempo consiste en acontecimientos interesantes, dignos de fotografiarse (Sontag, 2014: 21).

Para Bourgois y Schonberg los sujetos fotografiados en imágenes de violencia se tratan así mismo como objetos de lástima. Así:

Las fotografías fuertes obligan a los observadores a preguntarse qué sucede afuera de los bordes de la imagen- una sugestiva falta de información puede proveer el ímpetu para un pensamiento crítico cargado de interpretaciones personales. La fuerza de la fotografía 
deriva de una respuesta visceral y emocional, y esto hace vulnerable a lo que el observador proyecta (Bourgois y Schonberg, 2011: 2).

De esta manera, las fotografías 'fuertes' se desplazan hacia los lectores de ahí la importancia de un pie de foto destinado a promover un diálogo entre esta y los lectores, clarificando los diversos significados culturales existentes en estas. La multiplicidad de interpretaciones de las fotografías violentas implica descontextualizar la historia detrás de ella. Es por esto que al "dejar a una imagen hablar sus mil palabras puede resultar en mil mentiras" (Bourgois y Schonberg, 2006: 3). La fotografía periodística es un medio donde se combina la estética de la información espectacular y el sensacionalismo ofreciendo a los públicos miradas diversas de mundos inaccesibles.

Tomar una fotografía, para Bourdieu (2003), significa recabar un dato social e interaccionarlo con un hecho que implícitamente significa decir algo. La fotografía se encuentra regida por reglas externas al acto mismo como las estructuras objetivas de la sociedad moderna que muestran las reglas éticas y estéticas presentes en el acto mecánico de tomar fotografías. La fotografía periodística exige la construcción de un producto objetivo y realista, cuyo fin es de dar la posibilidad de captar fehacientemente el mundo de los objetos, es decir, de aprehender un supuesto.

Al respecto, desde una mirada crítica Bourdieu (2003) invita a dudar del acto fotográfico, porque dicho acto no es neutral, no es objetivo, existe un grado de subjetividad en lo que miramos, por tanto, en lo que fotografiamos. Sin embargo, ciertas prácticas fotográficas exigen un cierto realismo como es el caso de los documentos de identificación. Por tanto, las obras fotográficas son producciones sociales que muestran estructuras de clases, construcciones colectivas y significados sociales (Bourdieu, 2003). Cada foto revela las intenciones subjetivas del mundo social de clases, grupos, jerarquías sociales y disputas entre ellas. Comprender cada foto significa comprender el excedente de significación, lo que está fuera de la foto y a la vez está contenido en ella.

Walter Benjamin (2006) alega que en la fotografía el valor exhibitivo comienza a reprimir al valor culturaldestinadas hacia el servicio de instituciones de control estatal e institucional de los medios de comunicaciónque han convertido a estas en objetos simbólicos e informativos. Una noticia para llamar la atención de los lectores deben ir acompañados de una imagen, caso contrario parecería diluirse como algo importante. "Las fotografías se valoran porque suministran información" (Sontag, 2014: 31).

La fotografía periodística, en muchas ocasiones, implica el uso de la violencia simbólica (Bourdieu, 2003) para llamar la atención. Así, "Las fotografías de cuerpos mutilados sin duda 
pueden usarse [...] a fin de verificar la condena a la guerra, y acaso pueden traer al país, por una temporada, parte de su realidad a quienes no la han vivido nunca" (Sontag, 2014: 20). Por ello, y como lo sostiene Lapenda (2017) las fotografías de violencia tienen como fin ser demostrativas, aleccionadoras y pedagógicas.

\section{A modo de conclusiones}

Los medios de comunicación tienen determinadas estrategias para 'bombardear' de información a la población. El ruido, el parloteo, la chácara, el rumor, se destina para ocultar lo que existe detrás de un hecho noticioso, hoy la superficialidad se convierte en lo único visible y las personas se deslizan felizmente.

La comunicación no satisface nuestros deseos, sino que perpetua los existentes, eliminando cualquier intención de mirar, pues nos hace creer que todo ya está dado. Vivimos el tiempo de la comunicación reaccionaria que ha instaurado un nuevo despotismo comunicativo sometiendo a los individuos a una nueva forma de vida, frente a este panorama la única estrategia de resistencia es una actitud estética y ética del sentir.

De esta manera, en las narrativas mediáticas existe un secreto de tornarse invisible por exceso de exposición es el medio principal de las ideologías, las cuales constituyen un conjunto de opiniones y doctrinas ya preparadas, acríticamente adoptadas como sostén de la acción política. Por otro lado, la información se ha convertido en una simplificación y extrema banalización de las ideologías, un menoscabo del aspecto conceptual en favor de la emocionalidad.

La representación de la violencia en los medios de comunicación es una invitación a pensar que no puede percibirse de manera aislada y por tanto se debe evaluar su taxonomía: el encuadre, el lugar, las fuentes, los géneros periodísticos, los tipos de actores y acciones de la superficie de la información. Esta taxonomía se incrementa a un máximo de expresividad, alternado, en muchos casos, las dimensiones de los hechos a narrar. Se muestra los crímenes de una manera directa, los cuerpos mutilados, la sangre es el elemento más decorativo.

Los cuerpos de la crónica roja exteriorizan toda una iconografía de visibilidad del crimen, y de la muerte. No se trata solamente del cadáver exhibido, sino, también del desdoblamiento del cuerpo. Hay un afán por la demostración de la nitidez de la imagen en el mejor encuadre. Se trata de mostrar la crudeza de la muerte: escamaciones, pieles secas, mutilaciones, una representación de las víctimas de la violencia en su expresión más desinhibida y así inscribir en ese discurso las miserias de su propio de la violencia de su propia realidad. 
La intención parecería ser dejar que los cuerpos hablenpara elevar el interés del público. Los medios de comunicación dedicados a la crónica roja estructuran una producción de la muerte, del dolor y sufrimiento a partir de una materialidad iconográfica barroca.La explotación de las imágenes de violencia se ha convertido en un asunto imprescindible de los medios de comunicación. La crónica roja está atravesada por fuertes tensiones, es compleja, contradictoria, muy ligada a la cultura popular; pero no se puede confundir como una expresión de esta, entre los elementos de la cultura popular que toma de la crónica roja se pueden citar: imágenes barrocas, simplicidad narrativa, masificación del circuito de distribución mediática, lo hace refuncionalizándolos, distorsionándolos y asimilándolos a su lógica. En la crónica roja, los sujetos subalternos son revestidos de los más abyectos y, sin embargo, es el medio más consumido por ellos. Pero, desde nuestro punto de vista, su representación grotesca y abyecta, estas crónicas de su lado más oscuro y sórdido es una suerte de mercantilización de la violencia y los cuerpos.

\section{Notas}

(1) Se entiende el conjunto de actividades desarrolladas por los gobiernos que guardan relación con la búsqueda de finalidades sociales y redistribución a través de los presupuestos del Estado.

(2) Las sociedades posmodernas surgen a finales del siglo XX, donde el capitalismo se aleja de su origen industrial y se dirige hacia una economía basada en los servicios.

(3) Este tipo violencia forma parte de lo Bourgois (2009) llama violencia cotidiana, donde la búsqueda de sensaciones extremas es su mayor finalidad.

(4) Se relaciona con las dicotomías, donde los binarios es su mayor expresión.

(5) El así llamado horror a la democracia es un movimiento de ocultamiento de la memoria colectiva.

(6) Es vivir en la muerte. El hecho fúnebre de la realidad de la muerte en las sociedades preindustriales daba cuenta de la fragilidad de la existencia, por tanto, se requiere de un recuerdo material de sus seres queridos.

\section{Bibliografía}

Ardèvol, E. (2001). Representación y cultura audiovisual en la sociedad contemporánea. Barcelona: Editorial UOC.

Baudrillard, J. (1976). El intercambio simbólico y la muerte. Caracas: Monte Ávila Editores.

Beck, U. (2006). La sociedad del riesgo: hacia una nueva modernidad. Barcelona: Paidós.

Benjamin, W. (2006). La obra de arte en la época de su reproductibilidad técnica. México: Itaca. 
Berger, P. y Luckmann, T. (2001). La construcción social de la realidad. Buenos Aires: Amarrortu.

Bourdieu, P. (2000). La dominación masculina. Barcelona: Anagrama.

Bourdieu, P. (2003). Un Arte Medio: ensayo sobre los usos sociales de la fotografía. Barcelona: Editorial Gustavo Gili.

Bourgois, P. (2002). El poder de la violencia en la guerra y la paz. Apuntes de Investigación, VI(8), Universidad Nacional de Avellaneda, pp. 73-98.

Bourgois, P. y Schonberg, J. (2011). Política y estética fotográfica: una documentación crítica de la epidemia de VIH entre inyectores de heroína en Rusia y Estados Unidos. Revista cultura y droga, 18, pp. 29-40, Universidad de Caldas.

Caparrós, M. (2009). Una Luna. Buenos Aires: Anagrama.

Carrión, F. (2008). Violencia y medios de comunicación: populismo mediático. Urvio, Revista Latinoamericana de Seguridad Ciudadana, Facultad Latinoamericana de Ciencias Sociales, 5, pp. 7-12.

Castel, R. (2003). La inseguridad social ¿Qué es estar protegido? Buenos Aires: Manantial.

Cuarterolo, A. (2007). La muerte ilustre. Fotografía mortuoria de personajes públicos en el Río de la Plata. En Rodríguez, D. y Herrera, L. (compiladores). Imagen de la muerte (pp. 83-105). Lima: Universidad Nacional Mayor de San Marcos.

Elías, N. ([1982]2000). The civilizing process. Sociogenetic and Psychogenetic Investigations. USA: Blackwell.

Epele, M. (2010). Sujetar por la herida. Una etnografía sobre drogas, pobreza y salud. Buenos Aires: Paidós.

Freud, S. (1991). Obras completas. Tomo XV. Buenos Aires: Amorrortu.

García Canclini, N. (1989). Culturas híbridas: Estrategias para entrar y salir de la modernidad. México: Grijalbo.

Geertz C. (1996). Conocimiento local. Ensayos sobre la interpretación de las culturas. Madrid: Paidos.

Giddens, A. (1997). Consecuencias de la Modernidad. Madrid: Alianza Editorial.

Gómez Buendía, H. (septiembre de 2004). Un mundo triste. Semana, Bogotá.

Imbert, G. (2008). Conductas extremas, riesgo y tentación de muerte en la sociedad del espectáculo (nuevas formas y usos de la violencia). Mediaciones Sociales. Revista de Ciencias Sociales y de la Comunicación, 3, pp. 111-126.

Imbert, G. (2004). La tentación de suicidio. Madrid: Editorial Tecnos. 
Kessler, G. (2009). El sentimiento de inseguridad: sociología del temor al delito. Buenos Aires: Siglo Veintiuno.

Lapenda, A. (2017). Exhibir la muerte: fotografías póstumas de líderes políticos latinoamericanos asesinados en el siglo XX. Nuevo Mundo Mundos Nuevos. Images, mémoires et sons. Recuperado de http://journals.openedition.org/nuevomundo

Luhmann, N. (1997). Observaciones de la modernidad. Barcelona: Paidós.

Marcia, D. (2012). Ethos violento: las vertientes edificantes de la representación de la violencia. Revista Creatividad y fin de la imagen. Modos, medios, funciones y usos en el acontecimiento visual Creatividad y Sociedad, XIX. Recuperado de http://www.creatividadysociedad.com/articulos/19/Ethos\%20violento\%20las\%20vertient es\%20edificantes\%20de\%20la\%20representacion\%20de\%20la\%20violencia.pdf

Martín-Barbero, J. (2004). Bogotá: los laberintos urbanos del miedo. En Navia, P. y Zimmerman, M. (coords.). Las ciudades latinoamericanas en el nuevo (des)orden mundial (pp. 293-307). México: Siglo XXI Editores.

Membe. A. (2011). Necropolítica. Santa Cruz de Tenerife: Editorial Melusina.

Monsiváis, C. (2003). Que se lleven sus matanzas a otra parte, que no me dejan ver la telenovela. Ecuador Debate. Centro Andino de Acción Popular, 60, pp. 159-170.

Mouffe, C. (2011). En torno a lo político. México: Fondo de Cultura Económica.

Ochoa, S. (2014). El riesgo en la sociología contemporánea: de los riesgos sociales a los riesgos modernos. México: Universidad Nacional Autónoma de México:

Perniola, M. (2006). Contra la comunicación. Buenos Aires: Amorrortu.

Reguillo, R. (1996). Ensayo(s) sobre la(s) violencia(s): breve agenda para la discusión. Signo y Pensamiento, 29, p. 9-18, Bogotá.

Reguillo, R. (2007). Subjetividad sitiada. Hacia una antropología de las pasiones contemporáneas. E-misférica, Instituto Hemisférico de Performance y Política, 4(1). Recuperado de http://hemi.nyu.edu/hemi/es/e-misferica-41/199-e41-essay-subjetividadsitiada-hacia-una-antropologia-de-las-pasiones-contemporaneas.

Rincón, O. y Rey, G. (2008). Los cuentos mediáticos del miedo. Urvio, Revista Latinoamericana de Seguridad Ciudadana. Facultad Latinoamericana de Ciencias Sociales, 5, pp. 34-45.

Rincón, O. (2016). Los miedos mediáticos como el espectáculo del siglo XXI (un ensayo). En Focás, B. y Rincón, O. (coords.). (In)seguridad, medios y miedos: una mirada desde las experiencias y las prácticas cotidianas en América Latina (pp. 293-316). Cali: Facultad de Derecho y Ciencias Sociales, Universidad Icesi.

Rotker, S. (2000). Ciudadanías del miedo. Caracas: Rutgers University/Nueva Sociedad. 
Rosas-Cobos, L. y Sasia-Santos, P. (2016). Subpolítica Global: El poder de la sociedad civil organizada para hacer frente a la contaminación del aire. Revista En-claves del Pensamiento, $X(20)$, julio-diciembre, pp. 13-37. Instituto Tecnológico y de Estudios Superiores de Monterrey, Campus Ciudad de México Distrito Federal.

Sontag, S. (2014). Sobre la fotografía. Madrid: DeBolsillo.

Tagg, J. (2005). El peso de la representación. Ensayos sobre fotografías e historias. Barcelona: Gustavo Gili.

Useche, Ó. (2008). Miedo, seguridad y resistencias: el miedo como articulación política de la negatividad. Polis Revista Latinoamericana, 19. Recuperado de https://journals.openedition.org/polis/3893

Scheper-Hughes, N. (1997). La muerte sin Ilanto. Violencia y vida cotidiana en Brasil. Barcelona: Ariel. 